\section{University of New Hampshire}

Carsey School of Public Policy

\section{CARSEY RE}

National Fact Sheet \#35
RESEARCH

Summer 2017

\title{
Three in Ten Rural and Urban Medicaid Recipients May Be Affected by Potential Work Requirements
}

Andrew Schaefer and Jessica A. Carson

$\mathrm{T}$ The Affordable Care Act in 2010 gave states the option to expand Medicaid access to adults with incomes up to 138 percent of the federal poverty level. Thus more able-bodied and working adults have become eligible for Medicaid. In addition, several states have petitioned the federal government to have the option to enforce work requirements for those receiving Medicaid in their state. ${ }^{1}$ Specific waiver requests vary by state, but could have broad implications for Medicaid recipients across the nation, and typically include a requirement of able-bodied, adult Medicaid recipients to complete a certain number of hours spent working, or in some kind of other approved activity, like job training or looking for work. Children under age 19, pregnant or recently postpartum women, people with disabilities, and sole caretakers of young children are typically excluded from these proposed work requirements.

Research shows that most Medicaid recipients work in some capacity ${ }^{2}$ and that those potentially affected by the proposed employment requirements are disproportionately from vulnerable populations including racialethnic minorities, older adults, people with disabilities, and the least educated. ${ }^{3}$ This fact sheet builds upon this work by exploring whether rural and urban Medicaid recipients would be differentially affected by a work requirement. We choose to focus on Medicaid recipients through a rural/ urban lens because rural adults differ from their urban counterparts on a host of demographic characteristics. Further, labor markets vary across metropolitan status and are impacted by different forces. Consequently, one-sizefits-all policy changes have the potential to impact rural and urban places in different ways.

Close to one-third (31.3 percent) of adult Medicaid recipients would be potentially impacted by adding a work requirement because they likely did not work enough in the past year or were engaged in some other non-exempt activity. This share is similar in rural and urban places (31.8 percent and 31.2 percent, respectively).

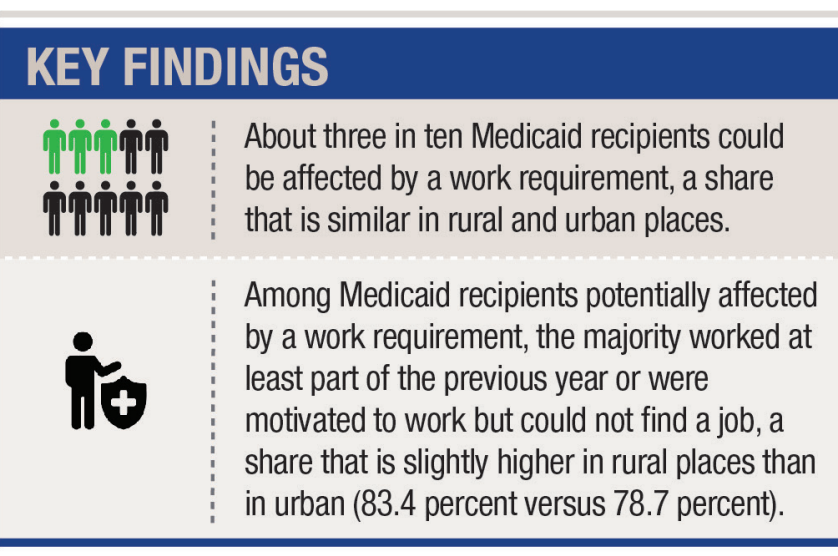

Among those potentially impacted, the vast majority worked for at least part of the year or were motivated to work but couldn't find employment. ${ }^{4}$ These workers, who worked less than part time or less than a full year and those seeking work, make up around 80 percent of potentially impacted Medicaid recipients (83.4 percent in rural places and 78.7 percent in urban). The remainder of those potentially subjected to a work requirement reported that they did not work in the past year either because they were caring for a family member or the household ${ }^{5}$ or for some other reason they did not disclose.

Most Medicaid recipients would be exempt from potential work requirements-and the majority of those who would be subjected are already looking for work, or working at least some of the time. As state policy makers consider Medicaid-related work requirements, it is worthwhile to consider the administrative costs of implementing this kind of waiver alongside the benefits of cost savings associated with reducing Medicaid rolls, and the expenses related to increasing the uninsured low-income population. Further, as most of those subject to the potential work requirements are already undertaking these approved activities, legislators may want to consider the work opportunities available in their states alongside the potential costs of disruption in health insurance coverage for their 


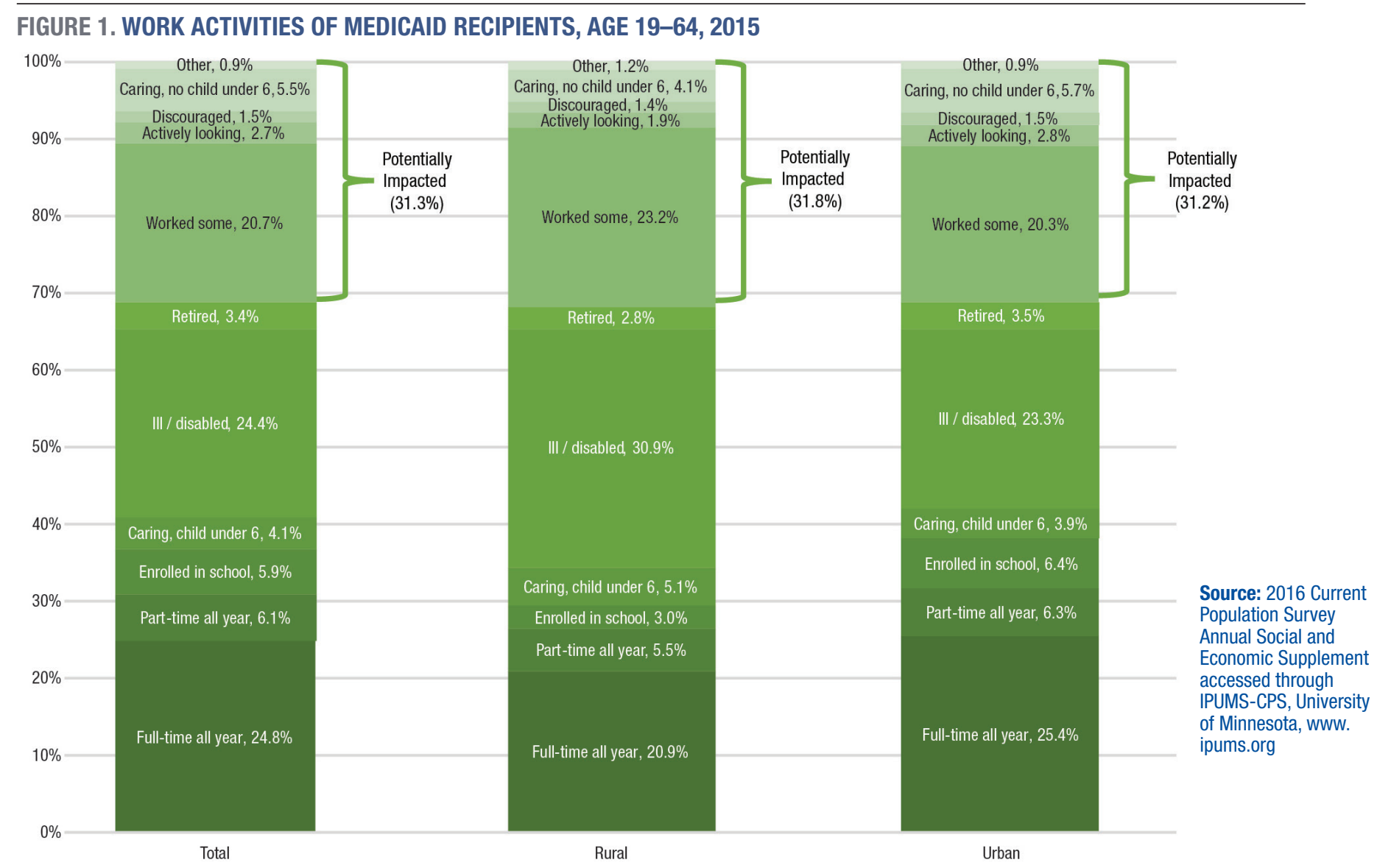

constituents, their families, and communities. The especially high share of those already working or looking for work in rural places may warrant additional consideration from legislators representing rural areas. In both rural and urban places, legislators should consider whether the consequences to families losing health insurance coverage outweigh the relative benefits of enforcing work requirements.

\section{Data}

The data for this project are from the 2016 Current Population Survey (CPS) Annual Social and Economic Supplement (ASEC), downloaded from IPUMS. ${ }^{6}$ All questions about income and health insurance refer to the previous year (2015). Readers should be cautious when comparing estimates between groups because the CPS is asked of a sample of the population, rather than the total population. Although some estimates may appear different from one another, it is possible that any difference is due to sampling error. Further, in some cases very small differences may be statistically significant due to the large sample size of the CPS. Nonetheless, all differences discussed in this brief are statistically significant $(\mathrm{p}<0.05)$.

\section{Endnot e s}

1. States are able to propose work requirements as part of their implementation of Medicaid expansion through a mechanism called a Section 1115 demonstration waiver. These waiver requests provide states with some options for flexibility in their delivery of Medicaid, allowing states to implement and test different approaches as long as some general criteria are still met. See https:// www.medicaid.gov/medicaid/section-1115-demo/about-1115/ index.html for details on Section 1115 demonstrations, or http:// www.kff.org/medicaid/issue-brief/key-themes-in-section1115-medicaid-expansion-waivers/ for a summary of waiver characteristics as implemented by specific states.

2. See http://www.kff.org/medicaid/issue-brief/understandingthe-intersection-of-medicaid-and-work/.

3. See http://healthaffairs.org/blog/2017/04/12/medicaid-workrequirements-whos-at-risk/.

4. This category includes those actively looking for work at least one month of the year and discouraged workers (that is, those who stopped looking because they couldn't find employment).

5. Excluding those with children under age 6, who would be excluded from the work requirement in most states; see http://www.kff.org/ medicaid/issue-brief/medicaid-and-work-requirements/.

6. Sarah Flood, Miriam King, Steven Ruggles, and J. Robert Warren, Integrated Public Use Microdata Series, Current Population Survey: Version 4.0 [dataset] (Minneapolis: University of Minnesota, 2015).

\section{About the Authors}

Andrew Schaefer, $\mathrm{PhD}$, and Jess Carson, $\mathrm{PhD}$, are research scientists in the Vulnerable Families program at the Carsey School of Public Policy at the University of New Hampshire (andrew. schaefer@unh.edu and jessica.carson@unh.edu).

\section{A ckn ow ledgments}

This work was supported by a grant from the Annie E. Casey Foundation. The authors thank Beth Mattingly, Michael Staley, Michael Ettlinger, Curt Grimm, Michele Dillon, Amy Sterndale, Laurel Lloyd, and Bianca Nicolosi at the Carsey School. 